\title{
CORRECTION
}

View Article Online

View Journal | View Issue

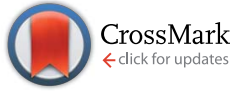

Cite this: J. Mater. Chem. A, 2016, 4, 12668

DOI: $10.1039 / \mathrm{c} 6 \operatorname{ta} 90155 \mathrm{~g}$

www.rsc.org/MaterialsA

\section{Correction: Simultaneous sulfur doping and exfoliation of graphene from graphite using an electrochemical method for supercapacitor electrode materials}

\author{
Nazish Parveen, ${ }^{a}$ Mohd Omaish Ansari, ${ }^{b}$ Sajid Ali Ansaria and Moo Hwan Cho*a \\ Correction for 'Simultaneous sulfur doping and exfoliation of graphene from graphite using an \\ electrochemical method for supercapacitor electrode materials' by Nazish Parveen et al., J. Mater. \\ Chem. A, 2016, 4, 233-240.
}

Due to errors in eqn (1) and (2) the following parts of the above paper have been corrected as described below.

On page 238 eqn (1) and (2) should be as follows: ${ }^{-5}$

$$
\begin{gathered}
C_{\mathrm{sp}}=\int I \mathrm{~d} V /(\Delta V M \nu) \\
C_{\mathrm{sp}}=I \mathrm{~d} t / m \mathrm{~d} v
\end{gathered}
$$

In the abstract on page 233 the specific capacitance exhibited by the S-GN electrode should be stated as $275 \mathrm{~F} \mathrm{~g}^{-1}$ at a current of $3 \mathrm{~mA}$.

On page 237 the specific capacitance of GN and S-GN should be reported as 70 and $81.25 \mathrm{~F} \mathrm{~g}^{-1}$ at $10 \mathrm{mV} \mathrm{s}^{-1}$ and 40.44 and 51.56 at $100 \mathrm{mV} \mathrm{s}^{-1}$, respectively.

On page 238 the capacitance values of the S-GN electrodes should be stated to be calculated as 275,260 and $120 \mathrm{~F} \mathrm{~g}^{-1}$ at 3,5 and $10 \mathrm{~mA}$, respectively.

On page 238 the maximum energy density should be reported as $9.6 \mathrm{~W} \mathrm{~h} \mathrm{~kg}{ }^{-1}$ at a power density of $375.7 \mathrm{~W} \mathrm{~kg}{ }^{-1}$ in $3 \mathrm{M} \mathrm{KOH}^{-1}$ electrolyte and an energy density of $4.1 \mathrm{~W} \mathrm{~h} \mathrm{~kg}^{-1}$ was maintained at a high power density of $1242 \mathrm{~W} \mathrm{~kg}^{-1}$.

The correct Fig. 7c and d are shown below.
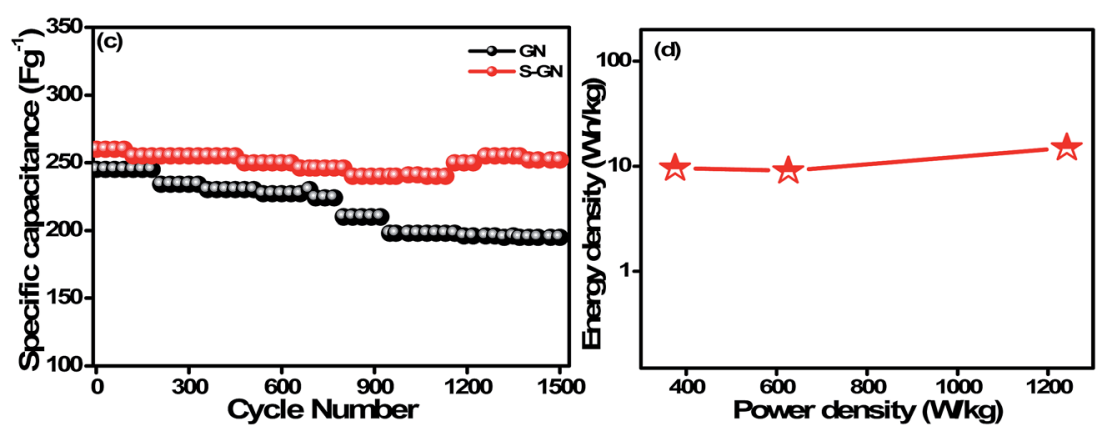

Fig. 7 (c) Cyclic stability test up to 1500 cycles and (d) Ragone plot ${ }^{2,3}$ of S-GN.

The Royal Society of Chemistry apologises for these errors and any consequent inconvenience to authors and readers.

${ }^{a}$ School of Chemical Engineering, Yeungnam University, Gyeongsan-si, Gyeongbuk 712-749, South Korea. E-mail: mhcho@ynu.ac.kr; Fax: +82-53-810-463; Tel: +82-53-810-2517 ${ }^{b}$ Centre of Nanotechnology, King Abdulaziz University, Jeddah 21589, Saudi Arabia 


\section{References}

1 H. Z. Chi, Y. Li, Y. Xin and H. Qin, Chem. Commun., 2014, 50, 13349.

2 J. Chang, H. Xu, J. Sun and L. Gao, J. Mater. Chem., 2012, 22, 11146.

3 W. Li, L. Xin, X. Xu, Q. Liu, M. Zhang, S. Ding, M. Zhao and X. Lou, Sci. Rep., 2015, 5, 9277.

4 X. Yu, Y. Kang and H. S. Park, Carbon, 2016, DOI: 10.1016/j.Carbon.2016.01.073.

5 Z. Khan, S. Bhattu, S. Haram and D. Khushalani, RSC Adv., 2014, 4, 17378. 